Maria Augusta Almeida Bursztyn, engenheira civil, consultora técnica da SEMA. Fez curso de especialização em engenharia sanitária pela

Escola Nacional de Saúde Pública - ENSP

(França) e doutorado de engenharia em ciências da água pela Universidade de Paris VI.

\title{
Conservação e utilização racional dos recursos hídricos
}

"Não há vida sem água. A água é um bem precioso, indispensável a todas as atividades humanas."

\section{Introdução}

Fator condicionante na organização e desenvolvimento das sociedades humanas, a água é responsável, em grande parte, pelo fenômeno da maior concentração populacional nos vales dos grandes rios e nas regiões costeiras.

Em função da renovação contínua da água através do ciclo hidrológico, ela é potencialmente inesgotável, fato que a diferencia dos outros recursos naturais, tais como petróleo, gás, carvão, etc. Estima-se que o volume total de água sobre a terra atinja aproximadamente 1.330 milhões de $\mathrm{km}^{3}, 0$ que representaria uma espessura de água de $2.600 \mathrm{~m}$ repartida sobre toda a superfície terrestre.

Entretanto, as reservas mais facilmente utilizáveis são bem mais reduzidas: em primeiro lugar, $98 \%$ deste enorme volume são constituídos de água salgada (cuja dessalinização exige o emprego de uma tecnologia dispendiosa); em segundo lugar, grande parte das reservas mundiais de água doce $(70 \%)$ se concentra sob a forma de gelo nas calotas polares e nos glaciares.

Mesmo considerando que as reservas globais de água são suficientes para assegurar as necessidades da humanidade, há que se levar em conta que a irregularidade de distribuição deste recurso natural no tempo e no espaço provoca excessos ou déficits em certas regiões, afetando o desenvolvimento econômico-social. Além disso, a situação é agravada como efeito da crescente degradação da qualidade das reservas de água doce.

Observa-se nestas últimas décadas que o crescimento da população mundial, ao lado da expansão das atividades agrícolas e industriais, acarretou, de forma generalizada, uma elevação acelerada da poluição das águas continentais.

O problema da poluição hídrica provocado por esgotos urbanos, metais pesados, pesticidas, adubos químicos, detergentes sintéticos, hidrocarbonetos, etc. representa um dos aspectos mais alarmantes da degradação do meio ambiente pelo homem. Uma das principais causas de mortalidade no Terceiro Mundo é a má qualidade da água, conseqüência do deficiente ou inexistente sistema de abastecimento e tratamento de água potável, bem como a da coleta e tratamento de águas residuárias. Estima-se que um em cada dois habitantes da América Latina sofre de algum tipo de doença de transmissão hídrica.

Entre os múltiplos usos dos recursos hídricos, a agricultura, a indústria e o abastecimento público apresentam-se como os responsáveis pelo maior volume de consumo efetivo. A parcela mais significativa do consumo mundial se deve à agricultura irrigada, atividade que vem aumentando como resposta ao crescimento da demanda humana por alimentos.

A água é uma matéria-prima essencial à maior parte das atividades industriais. Suas principais uti- 
lizações neste setor se dão, seja no processo de fabricação propriamente dito, seja na incorporação ao produto final, no resfriamento e produção de vapor, etc. Ainda que se tenha em conta que o consumo de água varia consideravelmente dentro de um mesmo ramo industrial, em razão de diferenças de padrão tecnológico, é importante assinalar a magnitude desta demanda. Por exemplo: a produção de $1 \mathrm{~kg}$ de papel requer, em média, $40 \mathrm{l}$ de água, a de $1 \mathrm{~kg}$ de açúcar, 100l, e a de $1 \mathrm{~kg}$ de aço, 201.

Quanto ao abastecimento público, verifica-se que a explosão demográfica do Século $X X$, associada à elevação do nível de qualidade de vida, contribuíram de forma significativa para a crescente demanda de água. No início do século, a população mundial era de menos de dois bilhões de habitantes e o consumo anual de água de $400 \mathrm{~km}^{3}$; hoje somos mais de quatro bilhões e consumimos aproximadamente $2.800 \mathrm{~km}^{3}$ anualmente.

A partir da projeção dos dados até aqui considerados, podemos inferir que a humanidade se confrontará brevemente com a crise da água. Contrariamente a outros recursos naturais, esta crise não se dará pela escassez, mas sim pela degradação de sua qualidade.

Evidencia-se então como urgente e prioritária a necessidade de racionalizar a utilização dos recursos hídricos. Para isso, é fundamental que uma ação de proteção de qualidade seja implantada paralelamente ao gerenciamento quantitativo da água no sentido de evitar um desequilíbrio entre a demanda e a disponibilidade dos recursos hídricos, permitindo, assim, satisfazer ou conciliar as necessidades crescentes dos setores em desenvolvimento: abastecimento em água potável das cidades e comunidades rurais, indústria, agricultura, navegação, produção de energia hidroelétrica, recreação, etc.

\section{A gestão das águas ${ }^{2}$}

Pode-se utilizar a expressão "gerenciamento dos recursos hidricos" para designar o conjunto de ações a serem desenvolvidas, visando garantir às populações e às atividades econômicas uma utilização otimizada da água, tanto em termos de quantidade como de qualidade.

Estas ações podem ser, conforme os casos, de caráter político, legislativo, econômico, de coordenação, de pesquisa, de formação de pessoal, de informação e de cooperação intersetorial, ou mesmo internacional.

O gerenciamento dos recursos hidricos, enquanto setor particular de atividade social, surgiu no início da era industrial. Foi uma espécie de reação natural, no momento em que a utilização intensiva da água para fins de produção e de consumo humano conduziu a que se considerasse a coleta, o tratamento e a distribuição da água como elementos do processo de produção propriamente dito.

A extensão e a importância do gerenciamento dos recursos hídricos, bem como a quantidade de medidas técnicas, jurídicas e econômicas a que este gerenciamento dá origem, variam em função das reservas hídricas disponíveis, de seu grau de aproveitamento e de determinantes econômico-sociais e políticos.

Do ponto de vista da estruturação administrativa, o gerenciamento dos recursos hídricos evoluiu de forma semelhante em vários países. Assim, enquanto a água é abundante e não ocorrem problemas graves de poluição, a responsabilidade pelo gerenciamento das águas vai-se repartindo, em geral sem grandes inconvenientes, entre as autoridades administrativas responsáveis pela sua utilização e conservação, de acordo com a vocação específica de cada setor da Administração e com as necessidades do momento. Porém, à medida em que se torna mais aguda a competição das atividades consumidoras, as funções dos diferentes setores da $\mathrm{Ad}$ ministração interessados na gestão das águas vão entrando cada vez mais em conflito, ocorrendo freqüentemente sobreposições e perdas de eficiência.

A gestão dos recursos hídricos exige, portanto, vários compromissos entre interesses freqüentemente opostos, evidenciando-se a necessidade de planejar-se e coordenar-se a utilização da água mediante o estabelecimento de estruturas que assegurem seu gerenciamento segundo uma perspectiva global.

Sendo a organização, composição e atribuições de uma estrutura de gestão, função de um conjunto de elementos condicionantes que variam caso a caso, torna-se impossivel apontar um modelo de estrutura com aplicação universal. Entretanto, todos os países que direcionaram a administração dos recursos hídricos dentro de uma perspectiva global procuram considerar a bacia hidrográfica como unidade básica de gestão.

Cunha et alii (1980) enumeraram outros princípios básicos orientadores de uma política de gestão dos recursos hídricos, dentre os quais podemos citar:

- o objetivo último de uma política de gestão das águas deve ser otimizar a utilização dos recursos hídricos, de forma a maximizar os benefícios para a coletividade, resultantes das diversas utilizações da água;

- a gestão dos recursos hídricos deve conside- 
rar a ligação estreita existente entre os problemas de quantidade e de qualidade das águas;

- a gestão das águas deve abranger tanto as águas interiores - superficiais e subterrâneas - como as águas marítimas costeiras;

- para pôr em prática uma política de gestão das águas é essencial assegurar a participação das populações através de mecanismos devidamente institucionalizados;

- a gestão dos recursos hídricos deve processar-se no quadro do planejamento territorial, visando compatibilizar - nos âmbitos regional, nacional e internacional - o desenvolvimento econômico e social com os valores do ambiente;

- a capacidade de autodepuração dos cursos de água deve ser considerada como um recurso natural, cuja utilização é legítima, devendo os benefícios resultantes dessa utilização reverter para a coletividade; a utilização dos cursos de água como meio receptor de efluentes rejeitados não deve, contudo, provocar a rotura dos ciclos ecológicos que garantem os processos de autodepuração;

- na definição de uma política de gestão das águas devem participar todas as entidades com intervenção nos problemas da água; todavia, a responsabilidade pela execução dessa política deve competir a um único órgão que coordene, a todos os níveis, a atuação daquelas entidades em relação aos problemas da água.

É importante ressaltar que a eficiência dos propósitos da gestão das águas está diretamente relacionada ao funcionamento coordenado dos instrumentos de gerenciamento, que se materializam através de diferentes âmbitos de atuação: administrativo, regulamentar, técnico e econômico.

No que diz respeito ao âmbito administrativo, responsável pelas questões do gerenciamento dos recursos hídricos, na experiência internacional, distinguem-se, de uma maneira quase constante, três níveis: nacional, que estabelece a legislação básica, regulamenta os procedimentos e funciona eventualmente como instância jurídica superior; regional, que se confunde com a jurisdição administrativa descentralizada ou assume a forma de uma agência especializada no gerenciamento de recursos hídricos; e local, que compreende os municípios, as indústrias e freqüentemente se estende à população ou a seus representantes, através de comitês consultivos e de associações.

É cada vez mais freqüente, na organização política da água, a coexistência de um organismo central de política e de controle e instituições regionais de aplicação e regionalização. Ou seja, observa-se uma tendência no sentido de centralizar o planeja- mento, a coordenação e o controle da gestão das águas e descentralizar a execução das ações de gestão.

A centralização das diretrizes e descentralização de sua aplicação são princípios comuns a vários países. O exemplo da República Federal da Alemanha é característico: o Estado Federal é quem fixa diretrizes gerais, enquanto que a fiscalização da aplicação é da competência dos estados (länder). As associações cooperativas alemãs, para a resolução dos problemas de água, constituem-se num grande exemplo de concepção e realização de uma estrutura de gerenciamento de recursos hídricos. Suas atribuições são geralmente as de assegurar o abastecimento público de água potável, coletar as águas residụárias e promover a respectiva depuração, bem como assegurar o abastecimento de água aos consumidores rurais e industriais.

Nos países de tendência centralizada (França, Japão e mesmo os Países Baixos), podem ser observados esforços de descentralização através de criação de serviços regionais. Na França, esta descentralização se traduziu pela criação dos organismos de Bacia - Agências Financeiras de Bacia e Comitês de Bacia - que são coordenados, a nível central, pelo Ministério do Meio Ambiente e da Qualidade da Vida, bem como por organismos interministeriais. Estas agências de Bacia são organismos públicos dotados de autonomia financeira, encarregados de ajudar financeira e tecnicamente a luta contra a poluição da água e o planejamento racional dos recursos hídricos.

Se, por um lado, o nível nacional se caracteriza como determinante do estabelecimento da estrutura legal, a região apresenta, por outro lado, o nível principal da implementação dos instrumentos econômicos. O exemplo das Agências Financeiras de Bacia, na França, que coordenam os financiamentos de todas as origens, assim como a cobrança de tarifas, é bem representativo. Na Inglaterra, a situação é análoga: as modalidades de taxação são da responsabilidade das autoridades regionais da água, que detêm neste país todas as responsabilidades no tocante ao usó da água, desde a captação até os efluentes.

No que diz respeito aos instrumentos jurídicos do gerenciamento da água, é importante assinalar que a aplicação de diferentes políticas, em diversos países, é condicionada a fatores, tais como: capacidades diferentes de assimilação da poluição pelo meio ambiente no seu estado atual, objetivos sociais diferentes, prioridades diferentes com relação à proteção do meio ambiente e graus diferentes de industrialização ou de densidade demográfica.

O controle do consumo da água pela via regu- 
lamentar é feito, em geral, através de um sistema de licenças ou de autorizações de captação das águas de superfície ou águas subterrâneas.

A adoção do sistema de autorizações de captação de água, com a finalidade de controlar e explorar os recursos hídricos, propicia aos organismos de gerenciamento um inventário atualizado das captações e permite especificar as condições de captação.

A regulamentação dos lançamentos de efluentes utiliza os mesmos procedimentos (autorizações, licenças e interdições) que são aplicados no caso das captações e se configuram através de normas de lançamentos.

É importante diferenciar as normas diretas, que se aplicam à quantidade ou qualidade dos lançamentos, das normas indiretas, que se expressam em termos de processos de produção elou de transformações de resíduos, níveis limites de utilização de certos materiais na fabricação, especificações relativas aos produtos finais, etc.

Os instrumentos econômicos de gerenciamento das águas se dividem em.duas grandes categorias: os meios de contribuição financeira, que permitem o levantamento de recursos (tarifas, taxas e impostos) e os instrumentos de financiamento (subvenções, empréstimos, isenções fiscais de diversos tipos).

A experiência tem mostrado em vários países que os incentivos econômicos, além das medidas técnicas, administrativas e legais, são absolutamente indispensáveis para chegar-se a um equilíbrio desejado entre a necessidade e disponibilidade dos recursos hídricos. No combate à poluição, estes incentivos econômicos têm conseguido incitar os usuários da água a engajarem-se nos programas propostos pelas autoridades de gerenciamento dos recursos hídricos.

As tarifas, quando fixadas a um nível apropriado e em função da qualidade e da quantidade das águas captadas e dos efluentes lançados, constituem um incentivo eficaz à limitação do consumo elou da poluição das águas. É importante assinalar que o nível de incentivo das tarifas de captação pode contribuir na luta contra o desperdício, principalmente no setor industrial.

Quanto às tarifas de poluição, elas proporcionam meios financeiros novos que se adicionam às fontes financeiras do Estado e permitem a realização de investimentos visando ao combate à poluição.

As ajudas financeiras podem efetuar-se sob duas formas: incentivos indiretos e dotações financeiras efetivas. No primeiro caso, o Estado utiliza diversas formas de redução dos encargos fiscais com a finalidade de custear uma parte das obras realizadas. No segundo, as ajudas são efetuadas sob forma de subvenções, adiantamentos e empréstimos a juros em condições privilegiadas. Na França, são geralmente os investimentos novos na luta contra a poluição que se beneficiam dessas ajudas (no caso das coletividades, as ajudas chegam a totalizar $70 \%$ do valor dos investimentos e,no caso das indústrias, $50 \%)$. Na Alemanha, as ajudas federais e dos estados (/änder) são dirigidas quase que exclusivamente às realizações públicas das coletividades. $\mathrm{Na}$ Inglaterra, todos os investimentos novos de caráter público recebem ajudas do Estado ou das autoridades regionais.

Enfim, vale ressaltar que, ainda que existam inúmeras particularidades no sistema de gerenciamento dos recursos hídricos de diferentes países que adotaram uma política de gestão integrada, de uma maneira geral, tanto os erros quanto os acertos de cada um deles têm contribuído para o aprimoramento dos demais.

\section{A experiência brasileira}

No caso do Brasil, uma das primeiras tentativas de equacionar, globalmente, o problema de desenvolvimento de uma bacia hidrográfica foi levada a efeito pela antiga Comissão do Vale do São Francisco - CVSF, criada em 1948. Outro exemplo é o da Comissão Mista Brasil-Uruguai, para a região compreendida pela Bacia da Lagoa Mirim, instalada em 1963, e incumbida de proceder aos estudos necessários para o desenvolvimento sócio-econômico da área.

Uma das mais recentes experiências em Administração por bacias refere-se à tentativa de conciliar os interesses conflitantes no uso da água, nas bacias do Alto Tietê e Cubatão, através de acordo firmado, em 1976, entre o Ministério das Minas e Energia e o governo do Estado de São Paulo. O sucesso obtido na aplicação desta sistemática, bem como da experiência internacional, inspiraram o governo federal, através dos ministérios das Minas e Energia e do Interior, a criar o Comitê Especial de Estudos Integrados de Bacias Hidrográficas - $\mathrm{CEEIBH}$, mediante a Portaria Interministerial n. 090/78 e que foi formalmente instalado em 1979.

O Comitê Especial é formado por representantes dos seguintes órgãos: Secretaria Especial do Meio Ambiente - SEMA, Departamento Nacional de Águas e Energia Elétrica - DNAEE, Centrais Elétricas Brasileiras - Eletrobrás, Departamento Nacional de Obras e Saneamento - DNOS, Superintendência do Desenvolvimento da Pesca - Sudepe, Secretaria Especial da Região Sudeste - Serse, e secretarias estaduais e superintendências de desenvolvimento regional. 
O CEEIBH tem por finalidade realizar o estudo integrado e acompanhar a utilização dos recursos hídricos das bacias hidrográficas dos rios federais, tendo em vista garantir o seu aproveitamento múltiplo e a minimização de conseqüências nocivas ao meio ambiente. No atendimento dessa finalidade o Comitê Especial objetiva: facilitar aos órgãos e entidades interessadas o conhecimento da disponibilidade de água para satisfazer a demanda dos usos prioritários; incentivar a melhoria das condições sanitárias das bacias hidrográficas dos rios federais; aumentar a eficiência e a atuação harmônica dos órgãos e entidades responsáveis pela prevenção e controle de situações críticas das bacias; realizar estudos e planejamentos coordenados que possam servir de subsídios para o licenciamento de atividades e execução de obras nas bacias; conjugar e entrosar os esforços dos órgãos e entidades federais, estaduais, municipais e particulares que exerçam atividades nas referidas bacias hidrográficas.

Para a realização de trabalhos de informação e suporte às atividades do $\mathrm{CEEIBH}$, são instalados comitês executivos, a nível de cada bacia hidrográfica considerada como prioritária. Dos comitês executivos participam representantes dos órgãos e entidades federais, estaduais, municipais e privadas, que atuam na referida área.

Estes comitês são encarregados de estudare apresentar recomendações ao CEEIBH, no tocante às providências normativas entendidas necessárias para o gerenciamento dos recursos hídricos da bacia, bem como de acompanhar a execução de estudos, projetos e trabalhos relativos ao aproveitamento múltiplo de tais recursos hídricos.

Até o presente, foram implantados comitês executivos para as bacias dos rios Paraíba do Sul CEEIVAP, Paranapanema - CEEIPEMA, Guaíba CEEIG, Iguaçu - CEEIRI, São Francisco - CEEIVASF, Jari - CEEIRJ, Paranaíba - CEEIPAR e Jaguari/Piracicaba - CEEIJAPI.

Estes comitês, devido a diversos fatores, encontram-se em fases distintas de evolução. Mesmo assim, já se pode identificar, a partir da experiência acumulada no desenvolvimento de suas atividades, alguns pontos críticos do atual sistema de gestão.
Os problemas são tanto de ordem estrutural, institucional, como, e principalmente, de ordem financeira.

A aplicação de uma política adequada de gestão das águas requer a participação dos usuários da bacia hidrográfica no planejamento da utilização múltipla das águas, bem como a implementação de mecanismos econômicos novos que viabilizem a execução desta política. A falta destes fatores, associada à fragilidade da estrutura organizacional dos comitês executivos como também do Comitê Especial, que não dispõe de instrumentos legais elou financeiros que assegurem a realização de seus objetivos, evidenciam a necessidade de reavaliação do modelo de gerenciamento atual no sentido de dinamizar o procesșo de aperfeiçoamento do uso dos recursos hídricos brasileiros.

\section{Notas}

1. Carta Européia de Água, proclamada pelo Conselho da Europa, artigo 1\%, Estrasburgo, 1968.

2. Este item sintetiza algumas idéias desenvolvidas por Maria Augusta Almeida Bursztyn e Sebastião Oliveira no trabalho Análise da experiência no gerenciamento dos recursos hídricos.

\section{Bibliografia}

BURSZTYN, Maria Almeida \& OLIVEIRA, Sebastião. Análise da experiência estrangeira no gerenciamento dos recursos hidricos. Brasília - SEMA/Minter, 1982.

Utilização racional dos recursos hídricos. Rio de Janeiro, Revista de Engenharia Sanitária - ABES, 21 (4), 1982.

BLANIC, Raymond. Eaux urbaines et eaux industrielles. S.1., S.I.N., 1973.

CHÉRET, Ivan. L'eau. Paris. Ed. Seuil, 1967.

CUNHA, Luis Veiga da et alii. A gestão da água; princípios fundamentais e sua aplicação em Portugal. Lisboa, Fundação Calouste Gulbenkian, 1980.

DEPARTAMENTO NACIONAL DE ÁGUAS E ENERGIA ELÉTRICA. Divisão de Controle de Recursos Hídricos. A gestão dos recursos hídricos no Brasil. Brasilia, 1981.

MINISTEERE DE L'ENVIRONNEMENT ET DU CADRE DE LA VIE. Le fil de l'eau. Paris, 1980.

RAMADE, François. Eléments d'écologie appliquée. S.1., Mc Graw Hill Inc., 1978.

SEPLAN/CNPq. III PBDCT: Ação programada em ciência e tecnologia: recursos naturais hídricos. Brasília, 1982. 


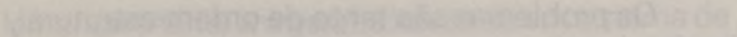

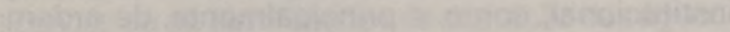
maramate

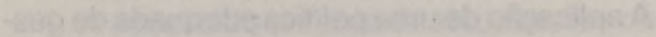

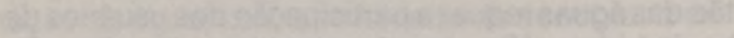

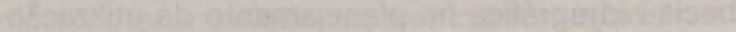

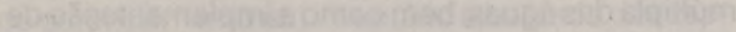

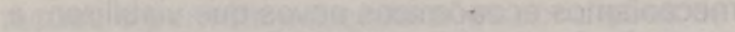

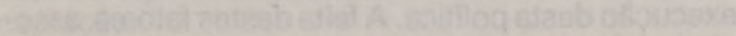

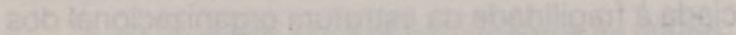

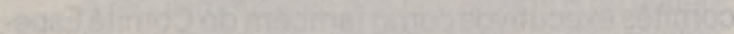

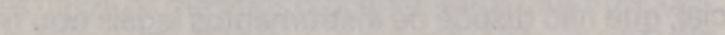

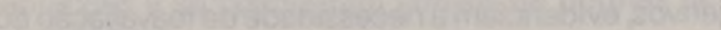

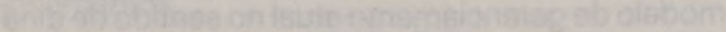

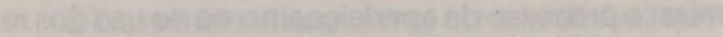

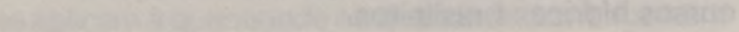

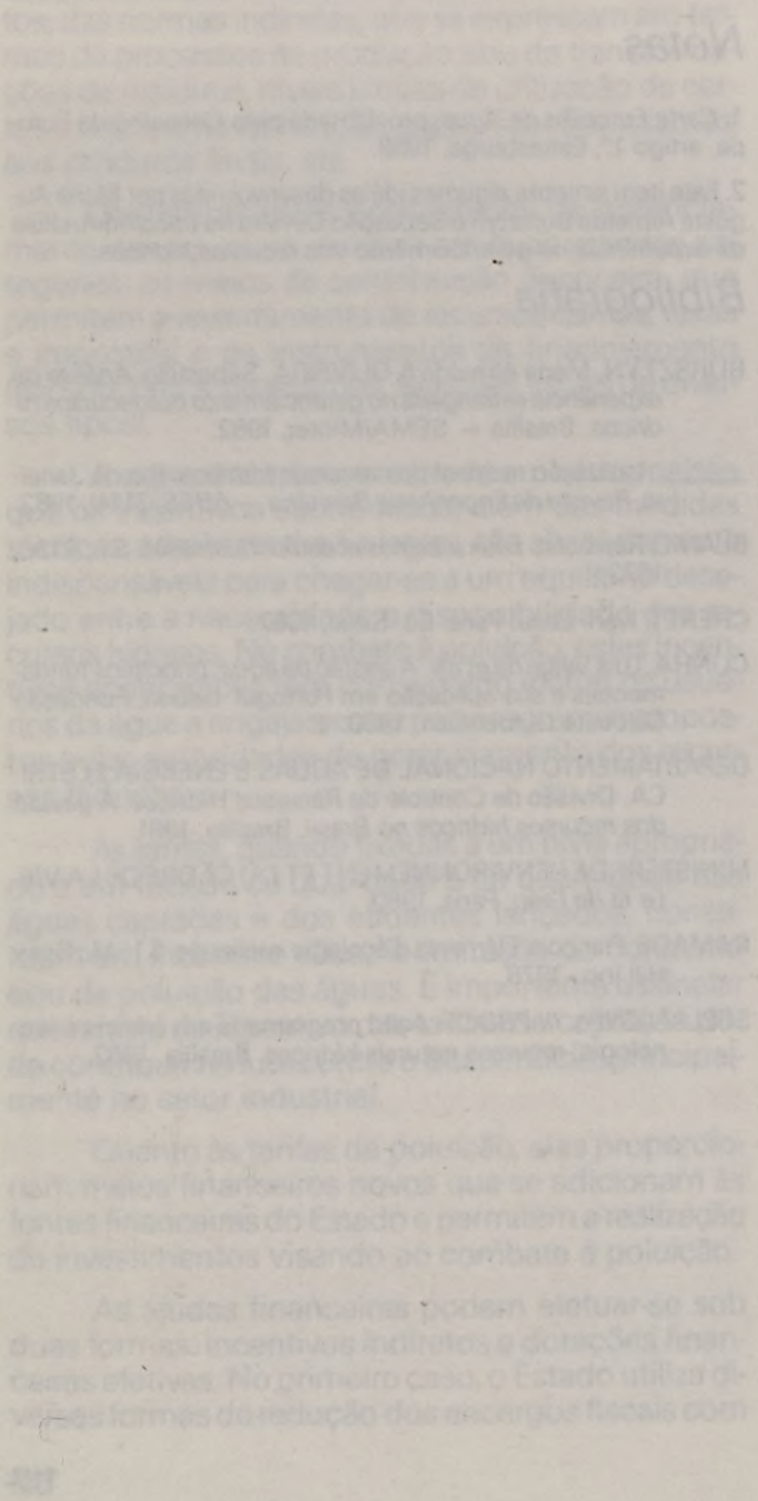

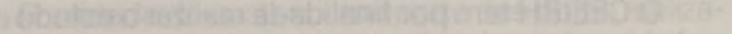

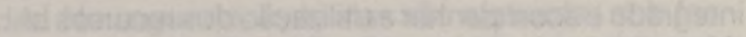

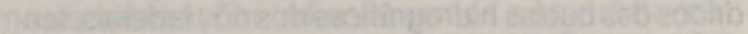

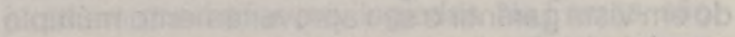

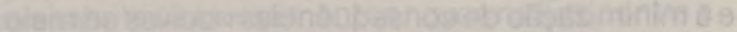

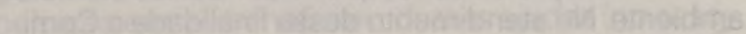

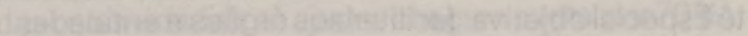

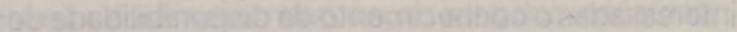

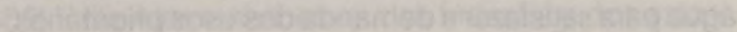

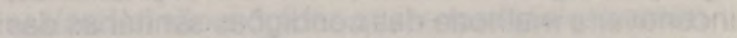

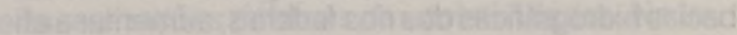

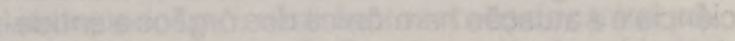

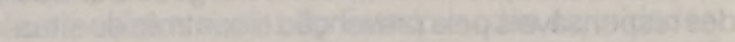

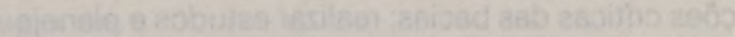

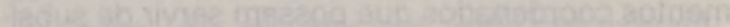

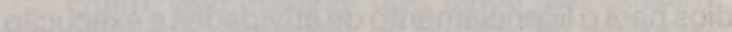

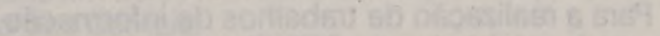

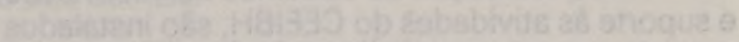

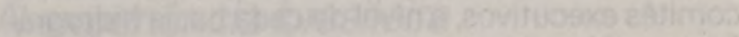

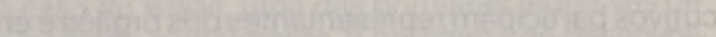

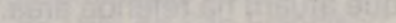

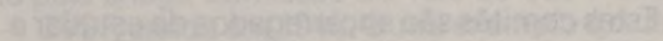

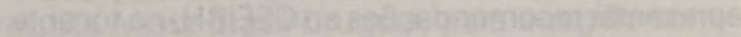

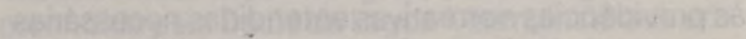

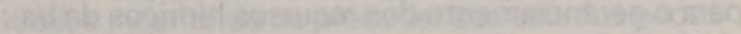

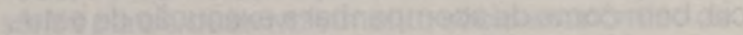

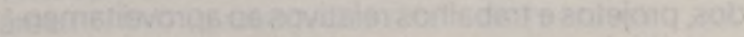
eoginteriti:

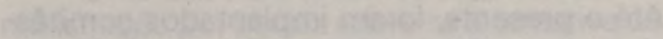

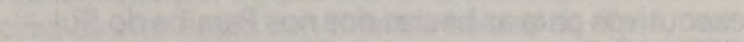

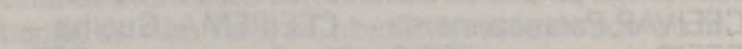
1720)

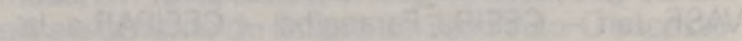

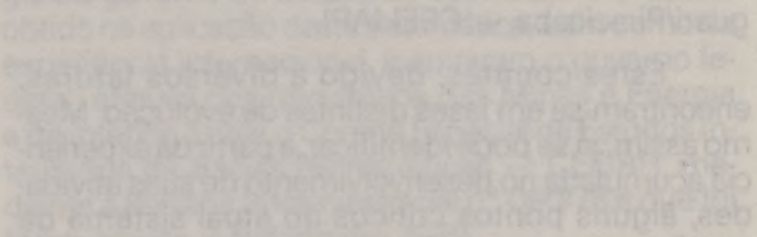

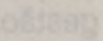

